\title{
BMJ Open Accidental death during pregnancy and puerperium from 2009 to 2019 in Hunan, China: a cross-sectional study
}

\author{
Fanjuan Kong, ${ }^{1}$ Aihua Wang, ${ }^{1}$ Jinping Su, ${ }^{1}$ Jian He, ${ }^{1}$ Donghua Xie,${ }^{1}$ Lili Xiong, \\ Xiaoqi Sheng, ${ }^{2}$ Zhiyu Liu (D) ${ }^{1}$
}

To cite: Kong F, Wang A, Su J, et al. Accidental death during pregnancy and puerperium from 2009 to 2019 in Hunan, China: a cross-sectional study. BMJ Open 2021;11:e047660. doi:10.1136/ bmjopen-2020-047660

- Prepublication history for this paper is available online To view these files, please visit the journal online (http://dx.do org/10.1136/bmjopen-2020 047660).

Received 07 December 2020 Accepted 05 August 2021

Check for updates

(C) Author(s) (or their employer(s)) 2021. Re-use permitted under CC BY-NC. No commercial re-use. See rights and permissions. Published by BMJ.

${ }^{1}$ Information Management Section, Hunan Province, Changsha, Hunan, China ${ }^{2}$ Psychology Department, Hunan Province, Changsha, Hunan, China

Correspondence to

Dr Zhiyu Liu;

327532957@qq.com

\section{ABSTRACT}

Objective Few studies have analysed accidental maternal deaths. This study analysed the basic situation and classification of maternal accidental deaths and compared the differences between urban and rural areas.

Design A cross-sectional study on accidental deaths during pregnancy and puerperium from 2009 to 2019 in Hunan Province.

Setting Hunan Province, with a population of 74 million, has an area of $210000 \mathrm{~km}^{2}$ and 123 counties/districts.

Participants A collection of 239 cases of accidental death during pregnancy and puerperium in Hunan Province from 2009 to 2019, including 181 cases of rural pregnancy and puerperium and 58 cases of urban pregnancy and puerperium.

Main outcome measure Classification of accidental mortality of pregnant women.

Results A total of 239 accidental deaths occurred in Hunan Province, with an accidental mortality rate of 2.8 per 100000 live births. The accidental mortality rate in rural areas (3.2 per 100000 live births) was higher than in urban areas (2.0 per 100000 live births). The proportion of accidental deaths among pregnancy-related deaths showed an upward trend. The main types of accidental deaths were suicide (1.0 per 100000 live births), traffic accidents (0.8 per 100000 live births), accidental poisoning/overdose and assault/homicide (0.2 per 100000 live births), and other accidents (0.6 per 100 000 live births). Maternal accidental deaths were mainly concentrated in low-income families, in rural areas and in those with low level of education. $74.5 \%$ of accidental deaths occurred before childbirth. $49.2 \%$ of pregnant women gave birth by caesarean section.

Conclusion In response to the different causes of accidental maternal death, public health programmes and policy interventions should pay special attention to maternal suicide and traffic injuries.

\section{INTRODUCTION}

Maternal mortality rate is an important indicator of maternal and infant safety. ${ }^{1}$ Maternal mortality rate in some developed countries declined in $2015,{ }^{2}$ and in China decreased from 88.8 per 100000 in 1990 to 17.8 per 100000 in 2019. ${ }^{3}$ However, there are only few articles all over the world that have studied accidental deaths during pregnancy and

\section{Strengths and limitations of this study}

There are few reports on accidental maternal deaths in China and this study fills this gap.

- The study sample includes all cases of accidental maternal deaths from 2009 to 2019 , which is representative and persuasive.

- The diagnostic criteria for accidental maternal death did not change and the changing trend in accidental maternal death was seen more clearly.

- This study does not further analyse what causes the accidents.

puerperium. Reducing accidental death has become an important measure to ensure the safety of mothers and their infants.

According to the $\mathrm{WHO}^{4}$ and the China Maternal Mortality Monitoring Program, ${ }^{5}$ maternal mortality monitoring refers to monitoring of women during pregnancy or within 42 days after termination of pregnancy, excluding deaths due to accidents (car accidents, poisoning, etc). In China, there are almost no reports in the literature of maternal deaths due to injury. Maternal mortality, whether due to homicide, suicide or pregnancy-related causes, is equally tragic, may be preventable and deserves national attention. ${ }^{6}$ The outline of the Healthy China 2030 Plan issued by the Communist Party of China (CPC) Central Committee and the State Council ${ }^{7}$ calls for the establishment of a comprehensive injury monitoring system, the development of technical guidelines and standards for key injury intervention, and the prevention and reduction of suicide and accidental poisoning. An issue of concern in China and the rest of the world is the study of the changing rules governing maternal mortality and causes of death and the proposal of targeted interventions to effectively reduce maternal mortality.

The possibility of accidental or intentional injury causing major trauma during 
pregnancy is increasingly considered a major contributor to maternal and infant mobility and mortality. ${ }^{89}$ Since more than half of all maternal deaths are considered preventable, public health interventions have the potential to enhance maternal health and other pregnancy outcomes. ${ }^{10}$ Accidental deaths are underestimated or excluded from maternal mortality reports, but have a significant impact on the ability of policymakers to understand potential social and family situations. Many countries have carried out targeted research on accidental maternal deaths. In Colorado, USA, ${ }^{11}$ self-injury (suicide and overdose) is the most common cause of pregnancyrelated death, and most deaths occur during the postpartum period. In New South Wales, Australia, ${ }^{12}$ trauma, including suicides, accidental injuries, motor traffic accidents and homicides, accounts for $73 \%$ of all maternal deaths (early and late) annually. In Ontario, Canada, ${ }^{13}$ more than $60 \%$ of maternal injury-related deaths were due to self-harm, poisoning/overdose and homicide. There are no specific data to show the developmental trend of accidental deaths and the situation of accidental death throughout pregnancy.

Through the maternal death reporting system in our province, it was found that the number of accidental deaths is increasing among pregnant women, which is a group that has not been fully studied. To more fully grasp the current situation of accidental maternal death in our province and to ensure the safety of mothers, this study included 239 cases of accidental deaths and analysed their distribution in urban and rural areas and the classification of causes of death. This study is the first to analyse the accidental deaths of pregnant women in China and is an important supplement to the study of accidental deaths of pregnant women in the country.

\section{DATA AND METHODS}

\section{Data sources}

Hunan Province is located in southeastern China, with an area of $21.18 \mathrm{~km}^{2}$ and a population of 73 million. Since 1990, the province has been included in the maternal and child health surveillance system. The death surveillance data used in this study were taken from the maternal and child health surveillance system of Hunan Province, which is based on the national maternal and child health surveillance system and includes all pregnancy and puerperium in 123 counties (cities) of Hunan Province.

The maternal and child health surveillance system follows strict data collection, reporting, audit and quality control procedures, which help reduce the risk of underreporting. This research is a cross-sectional survey of accidental maternal deaths in Hunan Province from 2009 to 2019. Monitoring data include information on the main cause of death, date and place of death, sex, and age. However, there is too much information missing on the gestational age of accidental deaths, which was not analysed in this study. The root causes of death were classified according to the WHO International Classification of Diseases 10th Edition (ICD-10)..$^{14}$

According to ICD-10, ${ }^{14}$ maternal death refers to the death of a woman during pregnancy or within 42 days after termination of pregnancy, regardless of the length of pregnancy and the location of pregnancy, due to any cause related to or aggravated by pregnancy or pregnancy management, but does not include deaths due to accidents (car accidents, poisoning, etc). The following conditions should also be reported as maternal deaths: maternal deaths due to anaesthetic accidents or drug allergies and maternal suicides caused by confirmed mental illness; and women with hydatidiform mole, including complete and partial hydatidiform mole, complications caused by hydatidiform mole and dying within 42 days after the last curettage, or hydatidiform mole developing into a trophoblastic tumour and causing death within 42 days after the last uterine curettage. All maternal deaths should be reported. Pregnancy-related death refers to the death of a woman during pregnancy or 42 days after termination of pregnancy, regardless of the cause of death. An accident refers to the death of a woman during pregnancy or puerperium caused by an accident not related to obstetrics. Pregnant women who die due to accidents are listed by subtypes of injury ${ }^{16}$ : intentional self-harm, transportation accident, accidental poisoning/ overdose, assault/homicide or others. Experts at all levels in China evaluate accidental deaths of pregnant women to determine the classification of cause of death. In addition, doctors must accurately describe injuries as intentional or accidental. In this paper, the accidental death of pregnant women refers to death not caused by pregnancy or pregnancy management, nor suicide caused by mental illness, as determined by experts.

\section{Data collection methods}

During the period from 1 January 2009 to 31 December 2019 , all pregnant women who died within 42 days from the start of pregnancy to termination of pregnancy were monitored. All pregnancies, live births and maternal deaths were identified by trained certified professionals.

- After receiving report of maternal death, this is immediately reported by county-level maternal and child health institutions to the local health administrative department and to the municipal and state-level maternal and child health institutions within 24 hours. Within 3 days after maternal death, special personnel, as well as township and village-level maternal and child doctors, midwives or individual practitioners, are organised to investigate the woman's medical history related to her death and to investigate and understand the medical history related to death, including pregnancy, delivery, postpartum conditions, course of onset and death, and medical history. If maternal death occurs at home and there is no healthcare worker present, relevant informed personnel visit the woman's home to investigate the death process and medical history. The death report card is then filled 
out and a summary of the medical record or of the death investigation is written down.

- The district, city and provincial levels respectively organise maternal death evaluation to determine the root cause of death, and one death evaluation occurs. After the provincial evaluation, the conclusion of the evaluation is written on the death report card. Once the review process is completed at all levels, the results are uploaded to the information system.

\section{Data quality control}

Data are collected and reported by experienced doctors and are checked for quality and accuracy at the county level by women's health institutions and by individuals. The community health service centre conducts quality inspections for service stations/neighbourhood committees and township health centres in villages using the monthly meeting system. The district, county, city and state organise a comprehensive quality inspection every quarter. The city and state conduct quality inspection and evaluation at least half a year. The provincial level monitors quality inspection and provides two reviews of monitored districts and counties every year. The districts and counties that do not meet the requirements will undergo a comprehensive leak investigation. Death data must be checked with the lists from civil affairs, public security, disease control and other entities to prevent underreporting and misreporting.

\section{Statistical analysis}

Statistical data were exported to Microsoft Excel V.2010. SPSS V.24.0 was used to analyse the ratios and proportions. $\chi^{2}$ test was used to compare the differences in accidental mortality between rural and urban areas. The Cochran-Armitage time trend test of mortality over time was carried out with SAS 9.4 software. $P$ values were assessed as two-tailed and $\mathrm{p}<0.05$ was regarded as the level of statistical significance.

\section{Patient and public involvement}

Patients and/or the public were not involved in the design, or conduct, or reporting, or dissemination plans of this research.

\section{RESULTS}

\section{Mortality trends related to accidental maternal deaths}

From 2009 to 2019, a total of 8574584 live births were monitored in our province, including 1957 pregnancyrelated maternal deaths, 1718 maternal deaths and 239 accidental deaths. The pregnancy-related mortality, maternal mortality and accidental mortality in our province were $22.6 \pm 5.5$ per $100000,19.8 \pm 5.3$ per 100000 and $2.8 \pm 0.7$ per 100000 , respectively. The proportion of accidental deaths among pregnancy-related deaths was on the rise, accounting for an increase of $75.11 \%$ from 2009 to 2019 (see table 1).

\section{Classification of causes of accidental deaths}

Intentional self-harm accounted for $35.6 \%$ of accidental deaths (including 25 cases of taking drugs/pesticides, 16 cases of jumping from buildings, 30 cases of drowning, 4 cases of hanging oneself and 10 cases of other causes), with a mortality rate of 1.0 per 100000 . Transportation accidents accounted for $30.1 \% \quad(n=72)$ of accidental deaths, with a mortality rate of 0.8 per 100000 . Accidental

\section{Table 1 Maternal mortality in Hunan Province from 2009 to 2019}

\begin{tabular}{|c|c|c|c|c|c|}
\hline Year & $\begin{array}{l}\text { Pregnancy-related } \\
\text { mortality } \\
\text { (per } 100000)\end{array}$ & $\begin{array}{l}\text { Maternal } \\
\text { mortality } \\
(\text { per } 100000)\end{array}$ & $\begin{array}{l}\text { Accidental } \\
\text { deaths } \\
\text { (n) }\end{array}$ & $\begin{array}{l}\text { Accidental } \\
\text { death rate } \\
(\text { per } 100000)\end{array}$ & $\begin{array}{l}\text { Accidental death/ } \\
\text { pregnancy-related death } \\
(\%)\end{array}$ \\
\hline 2009 & 30.2 & 27.1 & 24 & 3.1 & 10.2 \\
\hline 2010 & 33.0 & 30.2 & 22 & 2.8 & 8.4 \\
\hline 2011 & 23.6 & 21.5 & 17 & 2.1 & 9.0 \\
\hline 2012 & 24.1 & 21.8 & 19 & 2.3 & 9.4 \\
\hline 2014 & 24.1 & 20.4 & 29 & 3.7 & 15.4 \\
\hline 2015 & 21.0 & 17.5 & 27 & 3.5 & 16.5 \\
\hline 2016 & 22.6 & 18.9 & 30 & 3.8 & 16.7 \\
\hline 2017 & 20.4 & 17.5 & 24 & 2.9 & 14.1 \\
\hline 2018 & 17.9 & 15.0 & 20 & 2.8 & 15.9 \\
\hline $\begin{array}{l}\text { Cochran-Armitage trend test } \\
\text { Z value }\end{array}$ & -8.804 & -9.5919 & & 0.5242 & \\
\hline$P$ value* & $<0.001$ & $<0.001$ & & 0.6001 & \\
\hline
\end{tabular}

${ }^{*} \mathrm{P}$ values were assessed as two-tailed. 
Table 2 Classification of causes of accidental death during pregnancy and puerperium

\begin{tabular}{|c|c|c|c|}
\hline Classification & $\mathbf{n}$ & $\%$ & $\begin{array}{l}\text { Mortality rate } \\
\text { (per } 100000)\end{array}$ \\
\hline Intentional self-harm & 85 & 35.6 & 1.0 \\
\hline $\begin{array}{l}\text { Taking poison/ } \\
\text { pesticide }\end{array}$ & 25 & 10.5 & 0.3 \\
\hline Jump off a building & 16 & 6.7 & 0.2 \\
\hline Jump into the river & 30 & 12.6 & 0.3 \\
\hline Hang oneself & 4 & 1.7 & 0.0 \\
\hline Others & 10 & 4.2 & 0.1 \\
\hline Transportation accident & 72 & 30.1 & 0.8 \\
\hline $\begin{array}{l}\text { Accidental poisoning/ } \\
\text { overdose }\end{array}$ & 19 & 7.9 & 0.2 \\
\hline $\begin{array}{l}\text { Carbon monoxide, } \\
\text { moderate }\end{array}$ & 17 & 7.1 & 0.2 \\
\hline Food poisoning & 1 & 0.4 & 0.0 \\
\hline $\begin{array}{l}\text { Accidental use of } \\
\text { pesticides }\end{array}$ & 1 & 0.4 & 0.0 \\
\hline Assault/homicide & 13 & 5.4 & 0.2 \\
\hline Others & 50 & 20.9 & 0.6 \\
\hline Total & 239 & 100 & 2.8 \\
\hline
\end{tabular}

poisoning/overdose accounted for $7.9 \%$ (including 17 cases of carbon monoxide poisoning and 2 other cases), with a mortality rate of 0.2 per 100000 . Assault/homicide accounted for $5.4 \%$ of accidental deaths, with a mortality rate of 0.2 per 100000 , while other accidents accounted for $20.9 \%(n=50)$, with a mortality rate of 0.6 per 100000 (see table 2 for details).

\section{Classification and comparison of accidental deaths}

The accidental mortality rate in rural areas was higher than in urban areas. The types of accidental maternal deaths differed between urban and rural areas. Among them, the mortality rates of intentional self-harm, ingestion of poisons/pesticides and traffic accidents in rural areas were higher than those in urban areas (see tables 3 and 4 for details).

Epidemiological study on accidental deaths during pregnancy and puerperium

The sociodemographic and obstetric characteristics of women experiencing maternal death due to accidents and suicides are summarised in table 5 .

- Age distribution: pregnant women experiencing accidental death in the province were between 16 and 45 years old, with the largest number of deaths (36.8\%) occurring among women between 25 and 29 years old, followed by women between 30 and 34 years old (22.6\%). The proportion of accidental deaths among pregnant women of advanced age ( $\geq 35$ years old) was more than $10 \%$.

- Economic level: $28.9 \%$ of accidental maternal deaths occurred in families with a per capita income of more than $¥ 8000$ (approximately US\$1200) and $58.6 \%$ of accidental maternal deaths occurred in families with an income of less than $¥ 8000$ (approximately US\$1200). Accidental maternal deaths were mainly concentrated in low-income families.

- Household registration distribution: maternal deaths were mainly concentrated in rural areas, reaching $74.9 \%$.

- Educational level: the educational level of women experiencing accidental death was generally low: $50.2 \%$ with junior high school education, $9.6 \%$ with college and above, and $16.7 \%$ with primary school and illiterate background.

- Delivery: $74.5 \%$ of pregnant women experiencing accidental death did not give birth and $25.5 \%$ gave birth. Of the pregnant women, $49.2 \%$ delivered by caesarean section and $39.3 \%$ by natural delivery. A

Table 3 Accident occurrence during pregnancy and puerperium in urban and rural areas

\begin{tabular}{|c|c|c|c|c|c|c|}
\hline \multirow[b]{2}{*}{ Year } & \multirow[b]{2}{*}{ Urban live birth } & \multirow[b]{2}{*}{ Rural live birth } & \multicolumn{2}{|l|}{ Urban } & \multicolumn{2}{|l|}{ Rural } \\
\hline & & & $\begin{array}{l}\text { Accidental } \\
\text { deaths (n) }\end{array}$ & $\begin{array}{l}\text { Accidental death } \\
\text { rate (per } 100000 \text { ) }\end{array}$ & $\begin{array}{l}\text { Accidental } \\
\text { deaths }(n)\end{array}$ & $\begin{array}{l}\text { Accidental death } \\
\text { rate (per } 100 \text { 000) }\end{array}$ \\
\hline 2009 & 255649 & 525377 & 5 & 2.0 & 19 & 3.6 \\
\hline 2010 & 263350 & 534552 & 7 & 2.7 & 15 & 2.8 \\
\hline 2011 & 267356 & 538004 & 2 & 0.7 & 15 & 2.8 \\
\hline 2012 & 279088 & 559886 & 5 & 1.8 & 14 & 2.5 \\
\hline 2013 & 272312 & 549043 & 4 & 1.5 & 10 & 1.8 \\
\hline 2014 & 266739 & 513835 & 5 & 1.9 & 24 & 4.7 \\
\hline 2015 & 274312 & 506754 & 6 & 2.2 & 21 & 4.1 \\
\hline 2016 & 280271 & 515128 & 7 & 2.5 & 23 & 4.5 \\
\hline 2017 & 304202 & 530753 & 8 & 2.6 & 16 & 3.0 \\
\hline 2018 & 258183 & 447341 & 7 & 2.7 & 13 & 2.9 \\
\hline 2019 & 248782 & 383679 & 2 & 0.8 & 11 & 2.9 \\
\hline Total & 2970244 & 5604352 & 58 & 2.0 & 181 & 3.2 \\
\hline
\end{tabular}


Table 4 Composition of causes of accidental death during pregnancy and puerperium in Hunan Province from 2009 to 2019

\begin{tabular}{|c|c|c|c|c|}
\hline \multirow[b]{2}{*}{ Classification } & \multicolumn{2}{|l|}{ Urban } & \multicolumn{2}{|l|}{ Rural } \\
\hline & $\begin{array}{l}\text { Accidental deaths } \\
\text { (n) }\end{array}$ & $\begin{array}{l}\text { Accidental death rate } \\
\text { (per } 100 \text { 000) }\end{array}$ & $\begin{array}{l}\text { Accidental deaths } \\
\text { (n) }\end{array}$ & $\begin{array}{l}\text { Accidental death } \\
\text { rate (per } 100000 \text { ) }\end{array}$ \\
\hline Intentional self-harm & 21 & 0.7 & 64 & 1.1 \\
\hline Taking poison/pesticide & 2 & 0.1 & 23 & 0.4 \\
\hline Jump off a building & 7 & 0.2 & 9 & 0.2 \\
\hline Jump into the river & 8 & 0.3 & 22 & 0.4 \\
\hline Others & 4 & 0.1 & 6 & 0.1 \\
\hline Transportation accident & 14 & 0.5 & 58 & 1.0 \\
\hline Accidental poisoning/overdose & 2 & 0.1 & 17 & 0.3 \\
\hline Carbon monoxide, moderate & 2 & 0.1 & 15 & 0.3 \\
\hline Food poisoning & 0 & 0.0 & 1 & 0.0 \\
\hline Total & 58 & 2.0 & $179^{\star}$ & 3.2 \\
\hline
\end{tabular}

${ }^{*}$ There were 3 cases of accidental deaths in rural areas. The classification of accidental deaths is not clear.

total of $9.8 \%$ of pregnant women who had delivered had less than five antenatal examinations and $73.8 \%$ had more than five antenatal examinations.

- Diagnostic basis of cause of death: a total of $51.5 \%$ of deaths were diagnosed on a clinical basis and $44.4 \%$ were inferred.

\section{DISCUSSION}

To the best of our knowledge, this is the first study to analyse the characteristics of accidental maternal deaths in China. The main findings of our research are as follows: (1) the proportion of accidental deaths in pregnancyrelated deaths is on the rise; (2) the main types of accidental deaths are suicide, traffic accidents, accidental poisoning/overdose, injury/homicide and other accidents; (3) maternal accidental deaths are mainly concentrated in low-income families, in rural areas and in those with low level of education; and (4) $74.5 \%$ of accidental deaths occur before childbirth.

\section{Trend of accidental deaths during pregnancy and puerperium}

Many years ago, most women died of complications caused by pregnancy and childbirth, such as bleeding, infection and pregnancy-induced hypertension, and maternal mortality is usually associated with factors that are directly connected to pregnancy and childbirth. ${ }^{17}$ With improvements in medical standards and increase in people's health awareness, death of pregnant women in many countries has been controlled at a relatively low level. By 2019, the maternal mortality rate in Hunan Province continued to decline. According to the narrow definition provided by the WHO, the maternal mortality rate in 2019 was 9.5 per 100 000, which was already of low level. Although the accidental mortality rate shows a fluctuating downward trend, the proportion of accidental deaths in pregnancy-related deaths increased from $10.17 \%$ in 2009 to $17.81 \%$ in 2019 , reflecting an increase of $75.11 \%$. Because the number of deaths of pregnant women in our province is declining. The number of accidental deaths has not been well controlled, resulting in an increase in accidental mortality. At present, there are only a few studies on accidental deaths during pregnancy and puerperium in the world and we do not have relevant data from other countries. However, the accidental death during pregnancy and puerperium requires more care and attention from the society.

\section{Differences in accidental maternal mortality between urban and rural areas}

In this study, the self-harm rate during pregnancy and puerperium in urban areas is higher than other categories of accidental death.

The accidental mortality rate in rural areas was higher than in urban areas. In particular, mortality due to maternal self-mutilation, traffic accidents and poisons/ pesticides in rural areas was higher than in urban areas. This is consistent with the trend showing that maternal mortality rate in the rural areas of China ${ }^{18}$ was higher than in urban areas during the same period. The possible explanation is the accessibility of drug crops, which are widely used in rural areas, making it easier for people to commit suicide. ${ }^{19}$ The educational level of rural women is generally not high and they tend to go extremes after conflicts with their families and neighbours. ${ }^{20}$ In addition, complex roads and poor infrastructure in rural areas as well as poor rural healthcare systems ${ }^{21}$ also increase the risk of death due to injuries. 
Table 5 Demographic and obstetric characteristics of accidental deaths during pregnancy and puerperium in Hunan Province from 2009 to 2019

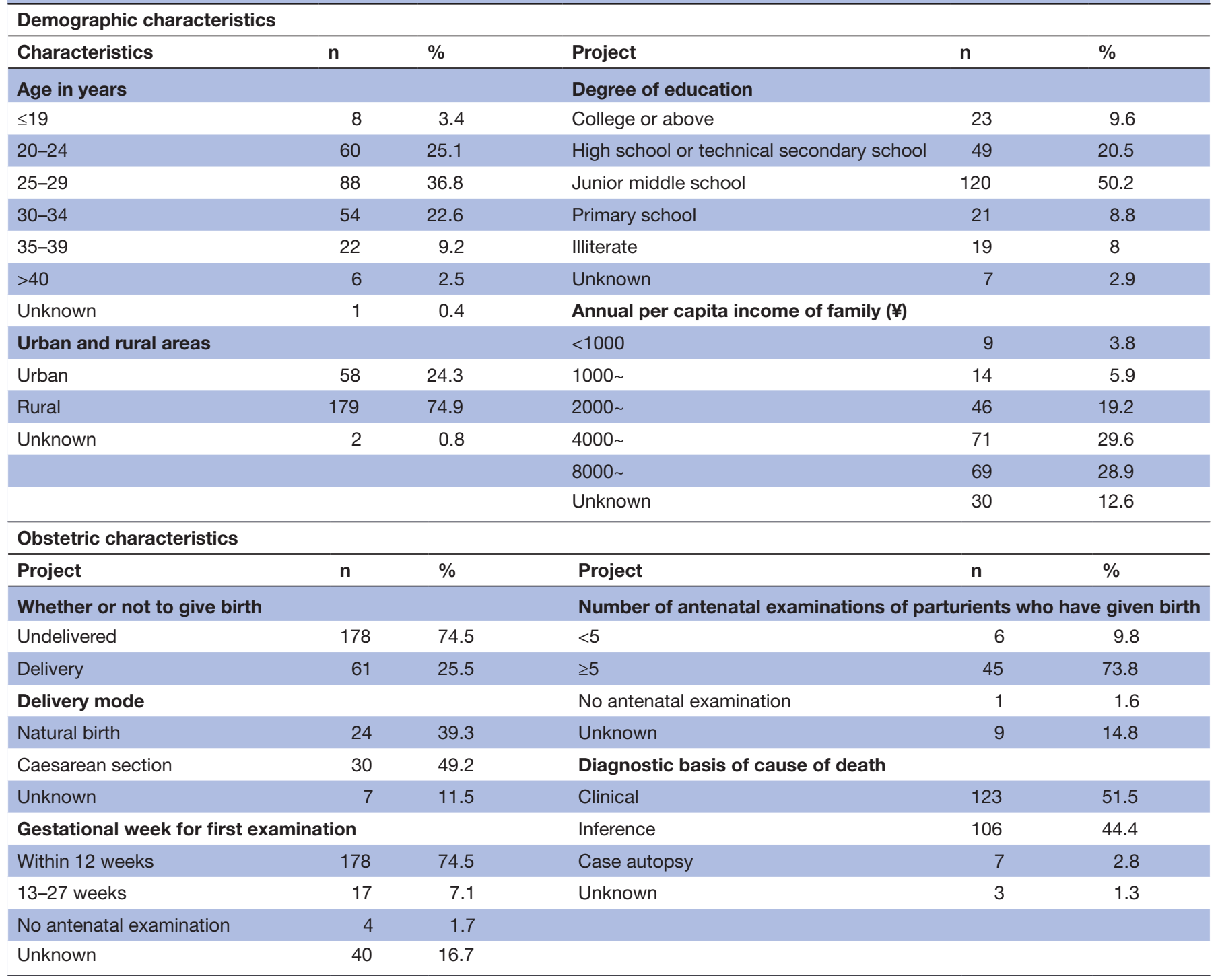

\section{Demographic characteristics}

The level of education obtained is an important indicator of early living conditions, ${ }^{22}$ and it may influence people's behaviour. Some studies ${ }^{23}$ have found that the level of education of a pregnant woman reflects her social status and is inversely proportional to maternal death; that is, the lower the level of maternal education, the less healthcare knowledge a woman has and the deeper the influence of old customs. ${ }^{24}$ In this research, the educational level of pregnant women who had accidental deaths was largely of low level, with the highest proportion of women having a junior high school education $(50.2 \%)$ and a primary school and illiterate background $(16.7 \%)$. Economic characteristics are also an important factor that affects maternal mortality. The practice of reducing maternal mortality in China shows that poverty is an important factor that affects maternal mortality. ${ }^{25}$ In this study, $58.6 \%$ of families experiencing accidental death had a per capita annual income of less than $¥ 8000$ (approximately US\$1200). Accidental deaths were more concentrated in low-income families.

In 2000, more than $67 \%$ of women experiencing maternal deaths in China had fewer than five antenatal check-ups or no antenatal check-ups. By 2013, the proportion had declined but remained as high as $50 \% \cdot{ }^{26}$ In this study, $74.5 \%$ of pregnant women who had accidental deaths underwent antenatal examinations in the early stage of pregnancy. Among the parturients who had given birth, $73.8 \%$ had undergone more than five antenatal examinations. This also reminds us that, in the process of prenatal check-ups, medical staff should pay more attention to the life and psychological health of pregnant women and teach more health education knowledge and that the society offer more help to women to avoid some accidental deaths. In the next step, we will continue to improve data collection to provide more convincing data on prenatal examinations. 
A total of $74.5 \%$ of accidental deaths in this research occurred prenatally; however, in Colorado, ${ }^{11}$ approximately $90 \%$ of self-harm deaths occurred post partum, with most of these women suffering from substance abuse and mental disorders. In New South Wales (20002006), ${ }^{12} 67 \%$ of deceased pregnant women had mental health diagnoses and/or mental health problems related to drug abuse. Among Australian women ${ }^{27}$ who gave birth, the proportion diagnosed with postpartum depression ranged from $10 \%$ to $20 \%$. In this study, we did not collect data on maternal mental and drug abuse, so the data cannot be compared directly; however, the data also suggest that we should strengthen the screening of and interventions for maternal emotional and mental health in a later study.

\section{Major types of accidental deaths}

Among rural residents, ingesting poison, hanging oneself, jumping into the river and electrocution are the main methods of committing suicide. ${ }^{28}$ In addition to mental illness and psychological distress, the causes of suicide are very complex, including collapse of social order, disintegration of families, misfortune in marriage, financial constraints, domestic violence, despair due to serious illness and other factors. ${ }^{29}$ Another risk factor is the universal accessibility of pesticides. According to the report 'Suicide and Suicide Prevention in Asia', ${ }^{30}$ the most common suicide tool used by farmers in China is pesticides, used in 62 out of every 100 suicides. In this study, the top three methods of suicide in rural areas were ingesting poisons, falling from buildings and drowning oneself in water. Similar to the situation in China, suicide is also a common cause of death among young people in the community abroad and is related to alcohol and drug abuse. $^{113132}$

Motor vehicle accidents are the leading cause of maternal mortality related to injury. ${ }^{334} \mathrm{China}^{3536}$ has the largest number of road traffic fatalities in the world. In this research, $30.1 \%$ of pregnant women died in traffic accidents, which is the second leading cause of death. China's rural areas have complex topography, lack road safety measures, and have an increasing number of vehicles and drivers with low awareness of traffic signs and rules, all of which can easily lead to all kinds of traffic accidents. Abiding by traffic rules has always formed the basis for road safety education in our country. The use of seat belts can reduce the risk of adverse maternal and fetal outcomes. ${ }^{37}$

There were 19 cases of accidental poisoning in this study, of which 17 cases were due to carbon monoxide poisoning, most by natural gas in the bath. Some poisonings occurred in rural areas and were caused by poor ventilation due to carbon heating in winter and the tight closing of doors and windows. Other accidental deaths include house collapse due to landslides, deaths caused by fires, bee venom and accidental falls, and so on.

\section{Limitations}

Our research results should be interpreted carefully considering some limitations. First of all, accidentrelated causes of death depend on the memories of family members and may be biased. However, after data quality control at the provincial, municipal and county levels and review of death cases with the public security and civil affairs departments, data quality and reliability are acceptable. Second, there are no data collected on the details of family background or on the urban and rural environment. Third, we were unable to obtain data on gestational age of accidental death among pregnant women. This is the next step we will focus on to improve the data we collect.

\section{CONCLUSION}

From 2009 to 2019, the proportion of accidental deaths in pregnancy-related deaths showed an upward trend, and differences between urban and rural areas still exist. The proportion is higher in rural areas than in urban areas, which is related to the underdevelopment of the social economy in rural areas. Self-harm and traffic accidents remain the main causes of accidental maternal death, with ingesting pesticides, jumping from buildings and falling into the river being the main methods of maternal self-harm. Therefore, accidental maternal mortality remains a public health problem that has not been deeply studied. Safety education and infrastructure should be strengthened to reduce accident-related deaths, and policies and programme such as safety education and psychological interventions should target the more vulnerable populations.

Acknowledgements Thanks to the staff of the medical institutions and maternal and child health institutions that collect and record maternal mortality cards.

Contributors FK drafted the initial manuscript and reviewed and revised the manuscript. AW, JH, LX, DX and JS designed the data collection instruments, collected the data, carried out the initial analyses, and reviewed and revised the manuscript. ZL and XS conceptualised and designed the study, coordinated and supervised the data collection, and critically reviewed the manuscript for important intellectual content. All authors approved the final manuscript as submitted and agree to be accountable for all aspects of the work.

Funding The study was funded by the Project of Hunan Provincial Department of Science and Technology (2018SK2064): topic: study on the prevention and treatment of adverse pregnancy outcome.

Competing interests None declared.

Patient and public involvement Patients and/or the public were not involved in the design, or conduct, or reporting, or dissemination plans of this research.

Patient consent for publication Not required.

Ethics approval The project was approved by the Medical Ethics Committee of Hunan Maternal and Child Health Hospital (no: EC20180319).

Provenance and peer review Not commissioned; externally peer reviewed.

Data availability statement Data may be obtained from a third party and are not publicly available.

Open access This is an open access article distributed in accordance with the Creative Commons Attribution Non Commercial (CC BY-NC 4.0) license, which permits others to distribute, remix, adapt, build upon this work non-commercially, and license their derivative works on different terms, provided the original work is 
properly cited, appropriate credit is given, any changes made indicated, and the use is non-commercial. See: http://creativecommons.org/licenses/by-nc/4.0/.

\section{ORCID iD}

Zhiyu Liu http://orcid.org/0000-0001-6534-3408

\section{REFERENCES}

1 Campbell OMR, Graham WJ, Lancet Maternal Survival Series steering group. Strategies for reducing maternal mortality: getting on with what works. Lancet 2006;368:1284-99.

2 Xiaowei M. China health statistics Yearbook, 2019. China Union Medical University Press

3 Statistical Bulletin on the development of health and health in China in 2019. Available: http://www.nhc.gov.cn/guihuaxxs/s10748/ 202006/ebfe31f24cc145b198dd730603ec4442.shtml

4 World Health Organization. Internation al statistical classification of disease and related health problem (ICD-10). 2. 10th revision. Geneva: WHO, 1993.

5 Division of Maternal and Child Health Services,, National Health and Family Planning Commission. National office of maternal and child health monitoring. Handbook of maternal and child health monitoring in China (2013 Edition). 26. Beijing: Monitoring Program of Maternal Mortality in China, 2013.

6 Perlow JH, Lesmes $\mathrm{H}$. Maternal mortality: time for national action. Obstet Gynecol 2014;123:362.

7 The CPC Central Committee and the State Council issued the outline of the healthy China 2030 Plan. Available: http://www.gov.cn/ zhengce/2016-10/25/content 5124174.htm

8 Chang J, Berg CJ, Saltzman LE, et al. Homicide: a leading cause of injury deaths among pregnant and postpartum women in the United States, 1991-1999. Am J Public Health 2005:95:471-7.

9 Deshpande NA, Kucirka LM, Smith RN, et al. Pregnant trauma victims experience nearly 2 -fold higher mortality compared to their nonpregnant counterparts. Am J Obstet Gynecol 2017;217:590. e1-590.e9.

10 Bernet P, Gumus G, Vishwasrao S. Maternal mortality and public health programs: evidence from Florida. Milbank Q 2020;98:150-71.

11 Metz TD, Rovner P, Hoffman MC, et al. Maternal deaths from suicide and overdose in Colorado, 2004-2012. Obstet Gynecol 2016;128:1233-40.

12 Thornton C, Schmied V, Dennis C-L, et al. Maternal deaths in NSW (2000-2006) from nonmedical causes (suicide and trauma) in the first year following birth. Biomed Res Int 2013;2013:1-6.

13 Ray JG, Zipursky J, Park AL. Injury-Related maternal mortality. Am J Obstet Gynecol 2018;219:307-8.

14 World Health Organization. International statistics classification of diseases and related health problem (ICD-10). 10th rev. Geneva: World Health Organization, 1993.

15 World health organization. Beyond the NUMBERS-Reviewing maternal deaths and complications to make pregnancy safer. China Union Medical University Press, 2006.

16 Ray JG, Zipursky J, Park AL. Injury-related maternal mortality. Am J Obstet Gynecol 2018;219:307-8.
17 The United Nations reports that steady progress has been made in reducing maternal mortality worldwide. Available: https://news.un. org/zh/story/2014/05/214142

18 Hong-ying Z, Feng D, Ju-hong LV. Analysis on the changes of maternal mortality in China from 1991 to 2016. Chinese Jounal of Family Palnning \& Gynecotokology 2019;11:34-7.

19 Huihui $\mathrm{H}$. Causes and preventive measures of high suicide rate of rural women. Legal System and Society 2012;11:11-182.

20 Jian C, Lu P. The main characteristics and intervention measures of suicide behavior of rural women in China. Social Work and Management 2017;17:12-17.

21 Xiang L, Wang K, Miao L, et al. Injury-related mortality among children younger than 5 years in China during 2009-2016: an analysis from national surveillance system. Inj Prev 2019;25:60-6.

22 Koch E, Romero T, Romero CX, et al. Impact of education, income and chronic disease risk factors on mortality of adults: does 'a pauper-rich paradox' exist in Latin American societies? Public Health 2010;124:39-48.

23 You F, Huo K, Wang R, et al. Maternal mortality in Henan Province, China: changes between 1996 and 2009. PLoS One 2012;7:e47153.

24 Zhibing X, Yanling L. Analysis of maternal mortality in Yunfu City from 2000 to 2010. Chin Med Sci 2012;2:122-3.

25 Jun Z, Juan L. Reduce maternal mortality to achieve the development goal of the year before last. Chin J Prev Vet Med 2011;3:8.

26 National Maternal and Child Health Surveillance Office. Analysis report on the main results of the National maternal and child health surveillance network in 2013, 2013

27 Schmied V, Johnson M, Naidoo N, et al. Maternal mental health in Australia and New Zealand: a review of longitudinal studies. Women Birth 2013;26:167-78.

28 JingJun, WuXueya Z. Research on the migration of rural women and the decline of Chinese suicide rate. China Agricultural University Journal of Social Sciences Edition 2010;27:20-31.

29 World Health Organization. Suicide prevention. Available: www.who. int/mental-health [Accessed 31 Jul 2010].

30 Hendin Het al. Suicide and suicide prevention in Asia. Geneva: World Health Organization, 2008.

31 Birgisdottir H, Bjarnadottir RI, Kristjansdottir K, et al. Maternal deaths in Iceland over 25 years. Acta Obstet Gynecol Scand 2016;95:74-8.

32 Goldman-Mellor S, Margerison CE. Maternal drug-related death and suicide are leading causes of postpartum death in California. Am J Obstet Gynecol 2019;221:489.e1-9.

33 Sirin H, Weiss HB, Sauber-Schatz EK, et al. Seat belt use, counseling and motor-vehicle injury during pregnancy: results from a multi-state population-based survey. Matern Child Health J 2007;11:505-10.

34 Sakamoto J, Michels C, Eisfelder B, et al. Trauma in pregnancy. Emerg Med Clin North Am 2019;37:317-38.

35 Tianzhu G. Research on traffic accident regulation analysis and Rreventive measures of China. Xi'an, China: Chang'an University, 2014.

36 Chu W, Wu C, Atombo C, et al. Traffic climate, driver behaviour, and accidents involvement in China. Accid Anal Prev 2019;122:119-26.

37 Vladutiu CJ, Marshall SW, Poole C, et al. Adverse pregnancy outcomes following motor vehicle crashes. Am J Prev Med 2013;45:629-36. 